\title{
High-Frequency Single-Board Doppler Minisodar for Precipitation Measurements. Part I: Rainfall and Hail
}

\author{
SHIXUAN PANG \\ Max-Planck-Institut für Meteorologie, Hamburg, Germany \\ HARTMUT GRAßL \\ Max-Planck-Institut für Meteorologie, and Meteorologisches Institut, Universität Hamburg, Hamburg, Germany
}

(Manuscript received 18 February 2004, in final form 30 August 2004)

ABSTRACT

\begin{abstract}
A high-frequency Doppler sodar for precipitation measurements has been developed. Such a Doppler sodar $(6-20 \mathrm{kHz})$ can almost always measure precipitation and turbulence spectra simultaneously. Therefore, the mean vertical wind and spectral broadening effects can be directly removed. As the acoustic refractive indices for ice and liquid water are almost the same, the acoustic retrieval of precipitation can also be applied to rain with small hail (e.g., diameter $D<10 \mathrm{~mm}$ ) or large hail, but for the latter, neglecting the effects of different orientations and shapes of hailstones.

The authors' single-board minisodar is based on the digital signal processing (DSP) technique. The first prototype has been continuously operated at a coastal weather station since 25 October 2002. For stratiform rain events, the minisodar showed good agreement with a Joss-Waldvogel disdrometer and an optical rain gauge. However, for convective heavy showers, the minisodar always observed higher rain rates.

The continuous, nonattended automatic operation of the minisodar has shown its capability for all kinds of precipitation measurements. The retrieval of precipitation rates for snow and graupel will be provided in a subsequent paper.
\end{abstract}

\section{Introduction}

Following the pioneering work of Little (1972), Weill et al. (1986) were the first to use a $6-\mathrm{kHz}$ minisodar for rain-rate measurements. Following this, Coulter et al. (1989) systematically investigated the use of a high-frequency minisodar $(4.5-7.5 \mathrm{kHz})$ as a rainfall sensor. A few studies of sodar application for precipitation measurements have been reported, for example, by Pang and Grassl (1994, 1995), Bradley (1996a,b, 1997), Grassl et al. (2000, 2002), and Pang et al. $(2000,2002)$. However, to the best of our knowledge, there is still no unattended automatic sodar for longterm routine measurement of precipitation. In particular, we know of no publication using a sodar for snow, graupel, hail, and mixed-phase precipitation measurements.

We have developed a single-board high-frequency Doppler monostatic vertically pointing minisodar for

Corresponding author address: Dr. Shixuan Pang, Max-PlanckInstitut für Meteorologie, Bundesstrasse 55, D-20146 Hamburg, Germany.

E-mail: pang@dkrz.de routine precipitation measurements. It is part of the project More Accurate Areal Precipitation Measurements Over Land and Sea (APOLAS) within the German Climate Research Programme (DEKLIM).

Since 25 October 2002, a minisodar prototype has been in continuous operation to measure precipitation at the Westermarkelsdorf Weather Station of the German Weather Service (DWD) on the island Fehmarn in the Baltic Sea.

At the same time, a Joss-Waldvogel (JW) disdrometer from the German Weather Service and an optical (OP) rain gauge developed by Kiel University have been deployed in this test field. The former is located about $24 \mathrm{~m}$ from the minisodar and the latter only about $15 \mathrm{~m}$. The distance between the JW disdrometer and OP rain gauge is $12 \mathrm{~m}$. The results of a comparison of three sensors will be given in two papers.

This paper, Part I, will describe the single-board sodar construction, the application for rainfall and hail measurements, and a part of the first long-term on-site operation. Part II will investigate the sodar potential to identify and to measure snow, graupel, hail, and mixedphase precipitation. 
a. Using high-frequency sodars to simultaneously measure precipitation and turbulence Doppler spectra

Microwave remote sensing techniques for rainfall measurements suffer from effects by the unknown mean vertical wind velocity $(\bar{w})$ and spectral broadening (Atlas et al. 1973; Lee 1988; Gossard et al. 1990; Wakasugi et al. 1986, 1987; Ulbrich 1992; Pang and Grassl 1994, 1995). To correct such effects, the Doppler spectra of precipitation and turbulence need to be measured simultaneously.

This is unfortunately not possible for small highfrequency microwave Doppler radars for rain measurements near the ground (e.g., monostatic and bistatic 10-GHz radar of Sheppard 1990a; 24- or 35-GHz radar of Duvernoy and Gaumet 1996) that have enough sensitivity to detect the Rayleigh scattering by raindrops but cannot detect Bragg scattering by turbulence. Lee (1988) concluded that for radar precipitation measurements the potentially high accuracy is often not reached because of the bias caused by the unknown mean vertical wind, leading to errors of up to a factor of 2 for rain rates. In contrast to the microwave refractive index of air, the acoustic index is about 1000 times stronger. Therefore, a high-frequency sodar can simultaneously measure not only the precipitation but also the turbulence spectrum (Little 1972; Coulter et al. 1989; Pang and Grassl 1994, 1995; Bradley 1996a,b). Mean vertical wind and spectrum broadening by turbulence can thus be directly observed and removed.

Figures 1a-f yield examples measured on 31 January 2004 to show both 1-min mean turbulence spectrum on the left side and the rain spectrum (averaging over 60 one-second spectra) for light rain (Figs. 1a,b), moderate rain (Figs. 1c,d), and heavy showers during a hurricane (Figs. 1e,f). The heavy rain case occurred during gale force winds and thus was a very hard test. The Doppler shift of the turbulence spectrum peak, that is, the first moment of the turbulence spectrum in Fig. 1, is a measure of the mean vertical wind velocity. From Fig. 1a, a mean vertical wind of $-0.05 \mathrm{~m} \mathrm{~s}^{-1}$ at $6-\mathrm{m}$ height, an updraft mean wind of $-0.38 \mathrm{~m} \mathrm{~s}^{-1}$ at 8 -m height, and an updraft wind of $-0.35 \mathrm{~m} \mathrm{~s}^{-1}$ at $10-\mathrm{m}$ height were retrieved, with a corresponding rain rate $R$ of $1 \mathrm{~mm} \mathrm{~h}^{-1}$. The mean vertical wind velocities retrieved from turbulence spectra in Figs. 1b-f are given in the figures.

\section{b. Using sodar for solid and mixed-phase precipitation measurements}

Hailstones are often a mixture of water and ice (List 1959; Macklin 1961; Bohren and Battan 1982). In this case, the high potential accuracy for a single conventional microwave radar observation cannot be reached (Balakrishnan and Zrnić 1990) as a result of the refractive index of ice being only about $20 \%$ of that for liquid water. Wilson (1970) reported that the average rain rate associated with a given radar echo intensity varies by a factor as high as 8 when rain and hailstorms are combined. Therefore, a high-frequency Doppler radar can only identify snow and rain with scores of $74 \%$ 95\% (Duvernoy and Gaumet 1996) rather than quantitatively measure snow or hail, because of their unknown liquid water content.

However, an acoustic sensor for ice and mixed-phase precipitation does not have this problem because the acoustic refractive indices are almost identical for ice and water.

Another considerable difficulty for high-frequency microwave radar arises from, first, a significant attenuation by precipitation and, second, the largely different attenuation of ice and water. In contrast, the acoustic attenuation in water and ice is small and can be neglected.

On the other hand, major limitations for a sodar are the significant acoustic attenuation by air, which strongly limits the sounding range, and sensitivity to ambient acoustic noise and mechanical vibration.

After a brief description of the rain retrieval principle in section 2, the construction principles of the single-board minisodar are given in section 3. Section 4 gives details about rain measurements during about the first month of operation from 25 October to 31 November 2002. In section 5, we report on mixed-phase precipitation measurement including hail.

\section{Short description of the rain retrieval principle}

The retrieval of raindrop size distribution $[N(D)]$ from sodar Doppler spectra (Little 1972; Coulter et al. 1989) is similar to that of Doppler radar (Wakasugi et al. 1986, 1987; Gossard 1988; Rajopadhyaya et al. 1993; etc.).

Through a fast Fourier transform (FFT), the Doppler signal time series is transformed into an amplitude spectrum, from which in turn the power spectrum in frequency domain $f$ or in velocity domain $w$ can be calculated by the relation $w=c_{a} f /\left(2 f_{a}\right)$, where $c_{a}$ is the acoustic velocity and $f_{a}$ is the acoustic frequency. Movement toward the sodar (down) is defined as positive. In the sodar equation, the backscattered power spectrum $P_{r}(w)$ is a combination spectrum $S_{0}^{\prime}(w-\bar{w})$ consisting of the spectrum due to backscattering by precipitation particles $S_{r}^{\prime}(w-\bar{w})$ and the spectrum caused by turbulent motion $S_{t}^{\prime}(w-\bar{w})$ :

$$
P_{r}(w)=P_{t} L e^{-\int_{0}^{r} 2 \alpha(r) d r} A_{v} S_{0}^{\prime}(w) / r^{2},
$$

where $S_{0}^{\prime}(w-\bar{w})=S_{r}^{\prime}(w-\bar{w})+S_{t}^{\prime}(w-\bar{w}) ; P_{t}$ is the power transmitted into the scattering volume $V$ of length $L ; \alpha(r)$ is the acoustic attenuation coefficient, which depends strongly on the temperature and humidity; $A_{v}$ is the effective antenna receiving area; and $r$ is the distance from the transmitter to the center of the scattering volume. 

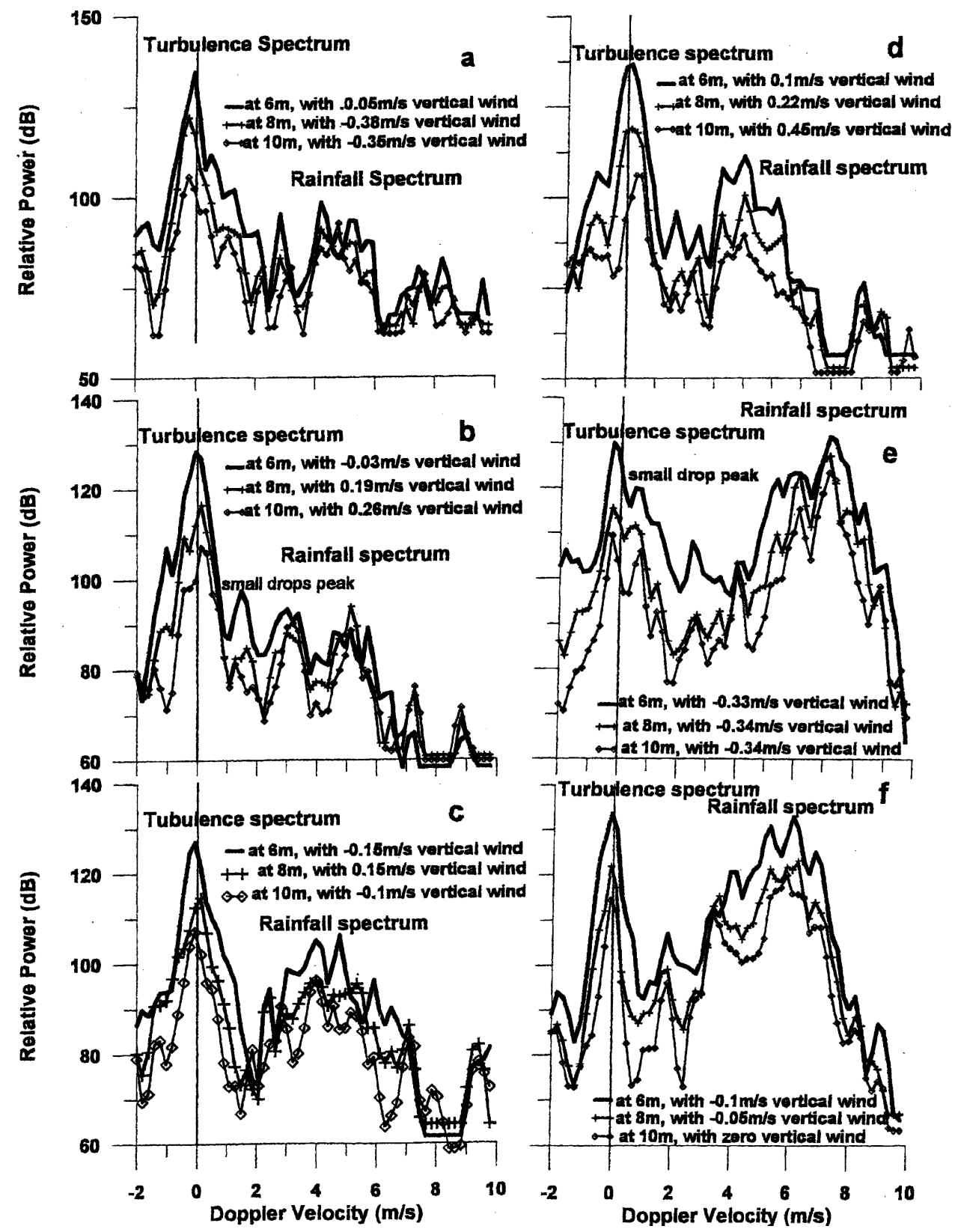

FIG. 1. Simultaneously measured rainfall and turbulence Doppler power spectra averaged over 1 min for 31 Jan 2004. (a) At $1331 \mathrm{UTC}$, rain rate $R=1.03 \mathrm{~mm} \mathrm{~h}^{-1}$; (b) at $1512 \mathrm{UTC}, R=1.52 \mathrm{~mm} \mathrm{~h}^{-1}$; (c) at 1337 UTC, $R=4.31 \mathrm{~mm} \mathrm{~h}^{-1}$; (d) at $1519 \mathrm{UTC}, R=5.34 \mathrm{~mm} \mathrm{~h}^{-1}$; (e) at $1537, R=44.58 \mathrm{~mm} \mathrm{~h}^{-1}$; and (f) at $1959 \mathrm{UTC}, R=50.14 \mathrm{~mm} \mathrm{~h}^{-1}$.

To reduce the spectral sidelobes, we use a Hamming window $W(w)$ in data processing. The rain spectrum $S_{r}^{\prime}(w-\bar{w})$ can then be expressed as the convolution of the precipitation Doppler spectrum $S_{r}(\omega)$ with the turbulence spectrum $S_{t}(w-\bar{w})$ and the window function $W(w): S_{r}^{\prime}(w-\bar{w})=S_{r}(w) * S_{t}(w-\bar{w}) * W(w)$. Similarly, the turbulence spectrum can be expressed as $S_{t}^{\prime}(w-\bar{w})$ $=S_{t}(w-\bar{w}) * W(w)$. Thus, we get

$$
S_{r}^{\prime}(w-\bar{w})=S_{r}(w) * S_{t}^{\prime}(w-\bar{w}) .
$$

Through a deconvolution of both observed spectra $S_{r}^{\prime}(w-\bar{w})$ and $S_{t}^{\prime}(w-\bar{w})$, the precipitation Doppler spectrum $S_{r}(\omega)$ can be derived. For Rayleigh scattering, $S_{r}(\omega)$ is related to drop diameter $D$ by

$$
S_{r}(w)=A N(D) \frac{25 \pi^{5}}{36 \lambda^{4}} D^{6} \frac{d D}{d w},
$$

where $A$ is a frequency-dependent calibration factor. 
Through a widely used empirical expression, drop terminal velocity $w$ is related to $D: w=9.65-10.30 e^{-6 D}$, where $w$ is in meters per second and $D$ is in centimeters (Atlas et al. 1973). Here, $N(D)$ and further integral rainfall parameters can then be derived from Eq. (3).

The deconvolution can be carried out by either iterative least square fitting (Gossard and Strauch 1990; Sato et al. 1990) or Fourier transform (Rajopadhyaya et al. 1993; Pang et al. 2000). The former needs an initial guess of $N(D)$, while the latter is rather sensitive to spectral noise. The accuracies of both methods depend strongly on the spectral fluctuations. A modeling approach for the Fourier deconvolution method can be found in Pang et al. (2000). In the Fourier deconvolution processing, we use a Gaussian fit to the turbulence spectrum instead of real one in order to avoid large unacceptable spectral fluctuations in the retrieved rain spectrum.

\section{a. Calibration of the minisodar by comparison to a disdrometer and an optical rain gauge}

To determine the calibration factor $A$, we employ an indirect calibration method. For example, we used a 14-h stratiform rain composed of separate 1-h time periods with rain, rather than single values measured by both the JW disdrometer and the optical rain gauge during a continuous rain event. The selection criterion for the chosen periods-weak winds in order to avoid the unknown wind impact on the JW disdrometer and the optical rain gauge-was applied.

\section{b. Imperfect response function}

We should point out here that raindrops falling in the turbulent atmosphere do not completely follow the motion of air as a result of their inertia and air viscosity. The raindrop falling velocity is therefore not exactly falling speed with respect to air minus mean vertical wind $\bar{w}$ (Bohne 1982) but should be smaller. We have derived an approximate imperfect response function (Pang and Grassl 1994, 1995). When correcting the influence of vertical wind on rain retrieval, the algorithm has to account for the imperfect response function.

\section{c. Acoustic attenuation compensation}

Coulter et al. (1989) have pointed out that a 1-dB error in the attenuation coefficient can result in errors of the rainfall parameter of $100 \%$. Assuming that temperature and humidity are constant up to about $20 \mathrm{~m}$ above surface, we have measured the surface temperature and humidity once per minute at one single height, from which an online calculation of acoustic velocity and attenuation coefficient in digital signal processing (DSP) follows. Because of a strong acoustic attenuation at high sodar frequencies, the attenuation compensation is carried out not only for each average height but also inside a range gate (Pang et al. 2002).

\section{d. System response correction and background noise subtraction}

Before each acoustic burst, the sodar measures the background noise spectrum twice. In addition, this also results in a measurement of the whole system frequency response including acoustic sensors, acoustic filter, electronics, and also digital filters. After subtracting this normalized system frequency response spectrum in decibels from the measured Doppler power spectrum, the spectral background noise subtraction is executed according to the generally accepted method put forth by Hildebrand and Sekhon (1974). Sometimes if the background noise is very strong and also is not white, the noise substraction leads to slight (false) rain rates of up to $0.2 \mathrm{~mm} \mathrm{~h}^{-1}$ for 1-min averages. However, by means of spectra averaging for a 1-s spectrum retrieval (see section $3 b$ ), the potential maximum false rain rate of $0.2 \mathrm{~mm} \mathrm{~h}^{-1}$ is reduced to about $0.06 \mathrm{~mm} \mathrm{~h}^{-1}$.

\section{e. Spectral overlap treatment}

In the case of rainfall with abundant smaller droplets, but also for drizzle and snowfall, the precipitation Doppler spectrum and the turbulence Doppler spectrum merge in the small Doppler velocity range as illustrated in Fig. 1. The combined spectrum in the overlap range is primarily the sum of two distributions: one corresponding to the Rayleigh scattering from small drops or snowflakes with low falling speed and another corresponding to the Bragg scattering from turbulence. Following the technique provided by Ralph et al. (1996) to distinguish the hydrometeor spectrum from the combined spectrum, we assume that the turbulence spectrum is approximately symmetric with respect to its peak velocity $v_{m}$. Subtracting the assumed corresponding part of turbulence spectrum from the measured overlapping spectrum, we obtain contribution to the spectrum arising from small drops or from snowflakes.

\section{Construction of a new minisodar}

The challenges for sodar development are high accuracy, reliability, and nonattended performance at low price.

Conventional sodars contain a rather complicated analog construction for both transmitter and receiver, whose relative errors increase as the received signal level decreases. To improve the measurement accuracy for sodars, one should take advantage of the rapidly developing computer technology, including the DSP technique. The DSP technique has at least partly been introduced for sodars by Coulter and Martin (1986) and Mursch-Radlgruber and Wolfe (1993), among others. Following them, we have developed a minisodar system based on the DSP technique with much simple sodar hardware, that is, a sodar on a single-combination DSP board (Grassl et al. 2000) that can be used as a sodar 
wind profiler, a sodar-disdrometer, and also a sound spectrum analyzer. The new sodar is composed of only two parts: first, an antenna including preamplifiers and, second, a common personal computer (PC) with a plugin DSP board as a working station operated by Microsoft Windows 98 or 2000. It can be operated with a Doppler velocity resolution as high as $3 \mathrm{~cm} \mathrm{~s}^{-1}$ depending on the FFT points selected.

Our first single-board minisodar prototype was applied for precipitation measurements.

\section{a. A sodar on a single board}

The core of the new system is a DSP-integrated plugin board. Except for the antenna and the analog amplifier, all other earlier functions of the transmitter and receiver hardware are now carried out by the software of a DSP.

On the DSP board, a DSP processor (TMS320C31) is combined with four $\mathrm{A} / \mathrm{D}$ input converters, two $\mathrm{D} / \mathrm{A}$ output converters with up to $250-\mathrm{kHz}$ sampling frequency, and $128 \mathrm{k}$-word 0-wait static RAM .

To optimize sodar operation, the DSP program is written in TMS320C3X Assembly with minimal program running time. In the host $\mathrm{PC}$, a Visual Basic program cooperates with DSP in the Windows environment to control the minisodar operation and data online processing.

The acoustic burst signal is generated by a subroutine of DSP and sent out from a D/A output to a power amplifier, which drives the acoustic transmitter.

As input, the DSP board needs only an amplified echo signal received by the acoustic sensors, which also act as an antialiasing filter. The turbulence and rainfall Doppler power spectrum are derived in real time, and they are all transferred to the host PC during the period without transmission. Furthermore, in the host PC, raindrop size distribution and rain rate, as well as other boundary layer parameters, can be retrieved online.

Almost all sodar operating parameters and meta can be selected from a menu on the PC.

\section{b. Digital heterodyne receiver}

We have developed three different digital receivers for sodar application, which can be found in Grassl et al. (2000, 2002). In this paper, we only discuss a digital heterodyne receiver configuration, which is shown in Fig. 2. The received signal sampled with frequency $f_{s}$ is multiplied with a reference signal of an intermediate frequency $f_{i}$ between 0.70 and $0.94 f_{a}$ depending on application, then filtered by a digital low-pass (LP) filter resulting in a Doppler signal (beat signal).

To simplify the program of the digital LP filter, the time series data sampled by any frequency $f_{s}$ has to be interpolated to a new dataset equivalent to one sampled by $f_{\text {so }}=80 \mathrm{kHz}$ for different $f_{s}$. The data are further decimated, and the equivalent sampling frequency shrinks to $f_{\mathrm{se}}=0.06$ to $0.2 f_{s}$ (e.g., $1-10 \mathrm{kHz}$ ) for

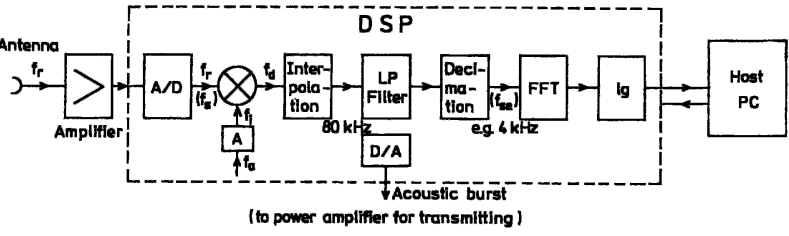

FIG. 2. Block diagram of the new single DSP board minisodar with a digital heterodyne receiver, where received signal $f_{r}=f_{a}+$ $\Delta f_{D}, \Delta f_{D}$ is the Doppler shift, and $f_{i}$ is intermediate frequency.

sampling the Doppler beat signal with maximum frequency of about $0.06 f_{a}$ for rain and $0.2 f_{a}$ for hail measurement. Therefore, the FFT points $N_{\mathrm{FFT}}$ can also be significantly reduced from, for example, 2048 or 4096 to 256 or 512 points, respectively. The frequency resolution $\Delta f$ or velocity resolution $\Delta \bar{w}$ can thus be significantly increased:

$$
\begin{gathered}
\Delta f=\frac{f_{\mathrm{se}}}{N_{\mathrm{FFT}}} \\
\Delta \bar{w}=\frac{\Delta f}{f_{a}} \frac{C_{a}}{2}=\frac{f_{\mathrm{se}}}{f_{a} N_{\mathrm{FFT}}} \frac{C_{a}}{2} .
\end{gathered}
$$

Normally $f_{\mathrm{se}}$ is about 5-18 times smaller than $f_{s}$, thus the resolution will increase about 5-18 times. For instance, if $f_{a}=10 \mathrm{kHz}$ and $f_{\mathrm{se}}=4 \mathrm{kHz}$, the $\Delta \bar{w}=6.6 \mathrm{~cm} \mathrm{~s}^{-1}$ for $N_{\mathrm{FFT}}=1024$, and $\Delta \bar{w}=13.2 \mathrm{~cm} \mathrm{~s}^{-1}$ for $N_{\mathrm{FFT}}=512$. Clearly, the heterodyne receiver manifests itself in a high spectral resolution.

Moreover, an average can be carried out during the data processing of one acoustic burst in order to suppress noise. We divide the Doppler signal data with sampling frequency of $f_{\text {so }}$ into $f_{\text {so }} / f_{\text {se }}$ data series with sampling frequency of $f_{\text {se. }}$. Then, through FFT, we get $f_{\text {so }} / f_{\text {se }}$ spectra that are further averaged to obtain the final spectrum. Although such $f_{\text {so }} / f_{\text {se }}$ data time series will not be completely independent, the spectral noise can still be significantly reduced by this averaging.

\section{c. An acoustic filter for ambient noise reduction}

A major challenge for measuring of rain parameters by sodars is the reduction of the impact by ambient noise effect that may even cause the saturation of the preamplifier, resulting in the loss of all rain information.

It follows from a principle of acoustics (Kinsler and Frey 1962) that a standing wave will be formed inside a tube when acoustic waves are propagating through a short open pipe whose diameter is much smaller than the wavelength. At the resonant frequency $f_{0}$ of such a pipe, the input impedance vanishes. In reality, at this frequency, the input impedance reaches a minimum, and the power emitted at the open end of the tube reaches a maximum for the acoustic pressure amplitude. Therefore, such a short tube acts like an acoustic bandpass (BP) filter. 
For instance, a BP filter with central frequency $f_{0}=$ $10 \mathrm{kHz}$, a bandwidth of about $\Delta f=1 \mathrm{kHz}$, and a quality factor $Q \approx 10$ is sketched in Fig. 3 . The bandwidth $\Delta f$ $\sim 0.1 f_{0}$ is suitable for rain measurements because the maximum Doppler shift of the return during rainfall corresponds to about $0.05 f_{a}$.

If each receiving sensor is combined with a smalltube BP filter, the total background noise level received directly by the acoustic sensors is reduced up to about a half. Therefore, the measurable minimum and maximum rain rates will also increase significantly.

\section{d. The antenna}

We designed two kinds of a $0.4 \mathrm{~m} \times 0.4 \mathrm{~m}$ antenna plate: 1) a piezo antenna with thirty-seven $50-\mathrm{mm}$ piezo tweeters as transmitter and receiver and 2) a microphone antenna with 20 or 24 microphones as receiver and a dynamic speaker as transmitter. An 0.8-m-high $15^{\circ}$ horn shield is used for reducing the disturbance by ambient noise and increasing the receiving effective area. The horizontal acoustic burst is vertically transmitted into the atmosphere by a $45^{\circ}$ reflector. The backscattering signal from turbulence and raindrops is received by the same antenna. Furthermore, the amplified signal is applied to the A/D converter on the DSP board for online processing.

The main problem of a piezo antenna is the resonance of the piezo element. After each transmission, a resonance with a frequency of about $4.5 \mathrm{kHz}$ always occurs lasting more than $50 \mathrm{~ms}$. Owing to this so-called ringing time, the minimum measuring height is limited to about $15-20 \mathrm{~m}$, which is too large for a high acoustic frequency above $10 \mathrm{kHz}$ because of the strong acoustic attenuation in air. Therefore, we prefer microphones to piezo elements, which also allows for an acoustic BP filter to be constructed easily on the antenna plate.

\section{Rain measurements}

To avoid disturbance to the neighborhood, we use a low transmitting power of only $3-5 \mathrm{~W}$. Thus the sound-

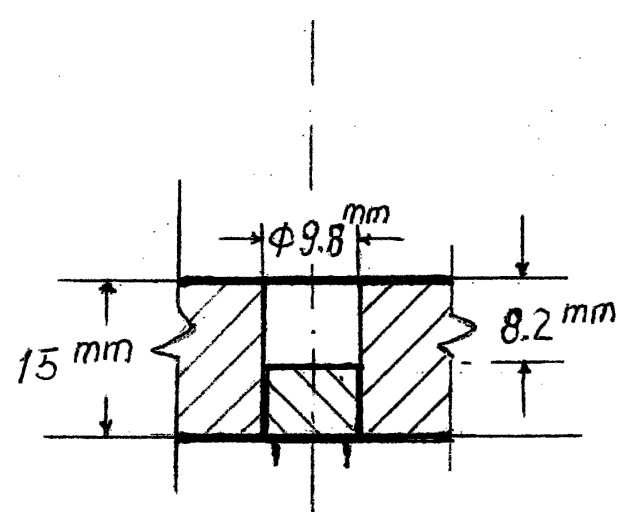

FIG. 3. Sketch of an acoustic BP filter with central frequency $f_{0}$ $=10 \mathrm{kHz}$. An acoustic sensor is mounted inside a small hole on the antenna plate. ing height was limited to $6-15 \mathrm{~m}$ for an acoustic frequency of $10.3-10.8 \mathrm{kHz}$.

Normally, each second, our minisodar transmits an acoustic burst of 50-ms length, and after about $10 \mathrm{~ms}$, the sodar begins to receive the echo in the form of Doppler spectra. Averaging over sixty 1-s spectra gives a 1-min spectrum, which is then transferred to the host $\mathrm{PC}$ for further processing. Note that frequency, time period, and number for averaging and height can be selected by a mouse click.

\section{a. Comparison of rain-rate measurements}

Because the timer of the PC suffered from quite a large temperature dependence (e.g., in winter it was running faster by about $25-45 \mathrm{~s}$ week $^{-1}$, while in summer it shrunk to about $10-20$ s week $^{-1}$ ), it is difficult to compare the 1 -min rain rates with other rain gauges. Therefore, we compare 1 -h average rain rates measured by our minisodar, a Joss-Waldvogel disdrometer of the German Meteorological Service, and an optical rain gauge developed by Kiel University.

Figure 4 displays such a comparison for $53 \mathrm{~h}$ of mostly stratiform rainfall, including only $4 \mathrm{~h}$ with heavy showers (points 1-4) for the period from 25 October to 30 November 2002. For $49 \mathrm{~h}$ with stratiform rain, the correlation coefficient of the minisodar measurements with the optical rain gauge measurements reaches 0.929 , whereas it is lowered to 0.822 when comparing with the JW disdrometer measurements. Including the heavy showers (points 1-4 in Fig. 4), the correlation coefficients fall to 0.844 for the optical rain gauge and only 0.801 for the JW disdrometer.

If we compare the time series of 1-min mean rain

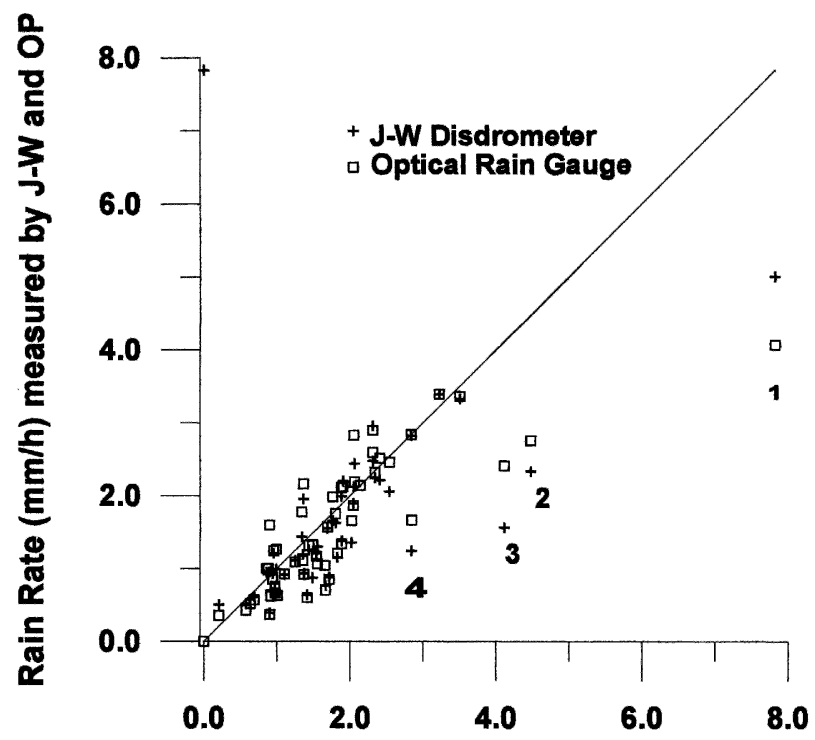

FIG. 4. Comparison of rain-rate 1-h mean measured by the minisodar, JW disdrometer, and optical rain gauge from 25 Oct to 31 Nov 2002. 
rates around $13 \mathrm{~h}$ on 27 October 2002 during a thunderstorm with heavy precipitation, lasting from 1315 to 1318 UTC as shown in Fig. 5, the maximum rain rate measured by the minisodar reached $111 \mathrm{~mm} \mathrm{~h}^{-1}$, while the JW disdrometer gave only $79 \mathrm{~mm} \mathrm{~h}^{-1}$ and the optical rain gauge gave even less $\left(43 \mathrm{~mm} \mathrm{~h}^{-1}\right)$. Again, the JW disdrometer and, even more so, the optical rain gauge underestimate rain rates under strong wind conditions. The heavy shower that lasted only a few minutes also included some hail or graupel, whose measurement we will discuss in more detail in section 5 .

It is obvious that good agreement of measured rain rates among three sensors can only be found for stratiform rain events; however, for heavy showers, the rain rates measured by the minisodar are remarkably higher. For the optical rain gauge, it could be that drops in the shadow of large drops are not detected or that some water drops might stick on the lens surface. The reason for the underestimation by the JW disdrometer will be discussed in the following section.

On average, the rain rates measured by the optical rain gauge were lower than for the JW disdrometer during heavy showers with strong winds, though the minisodar measurements show a higher correlation with the optical rain gauge than with the JW disdrometer.

\section{b. Comparison of measured drop size distributions}

During a heavy shower of only 4-min duration on 25 October 2002, the rain rate measured by the minisodar at 2308 UTC reached $13.7 \mathrm{~mm} \mathrm{~h}^{-1}$, while it is only measured to be $10.3 \mathrm{~mm} \mathrm{~h}^{-1}$ by the JW disdrometer. The corresponding size distributions $N(D)$ are shown in Fig. 6a. Two minutes later, as shown in curve A of Fig.

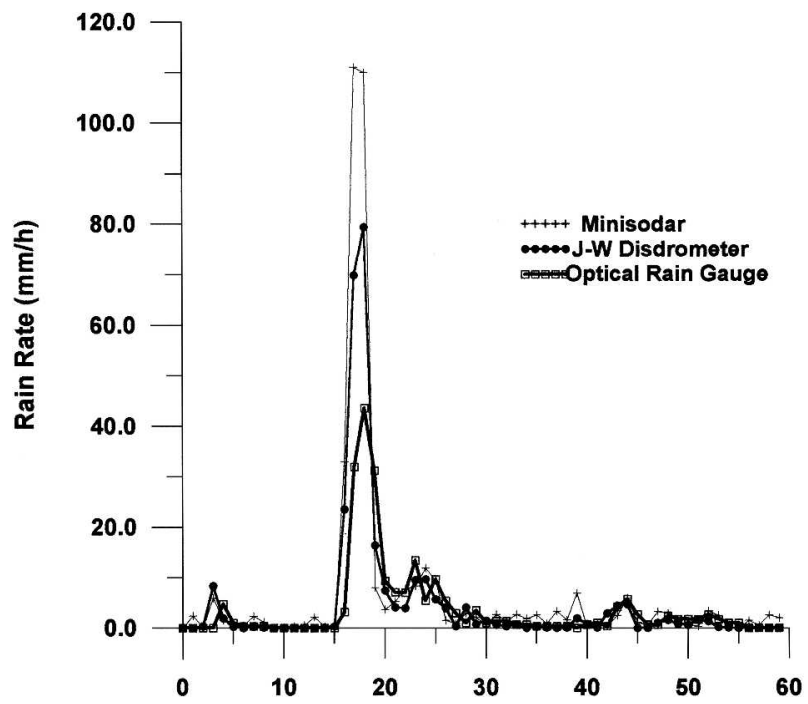

FIG. 5. Comparison of 1-min average rain-rate time series for $1 \mathrm{~h}$ from 1300 to 1359 UTC on 27 Oct 2002 measured by the minisodar, JW disdrometer, and optical rain gauge.
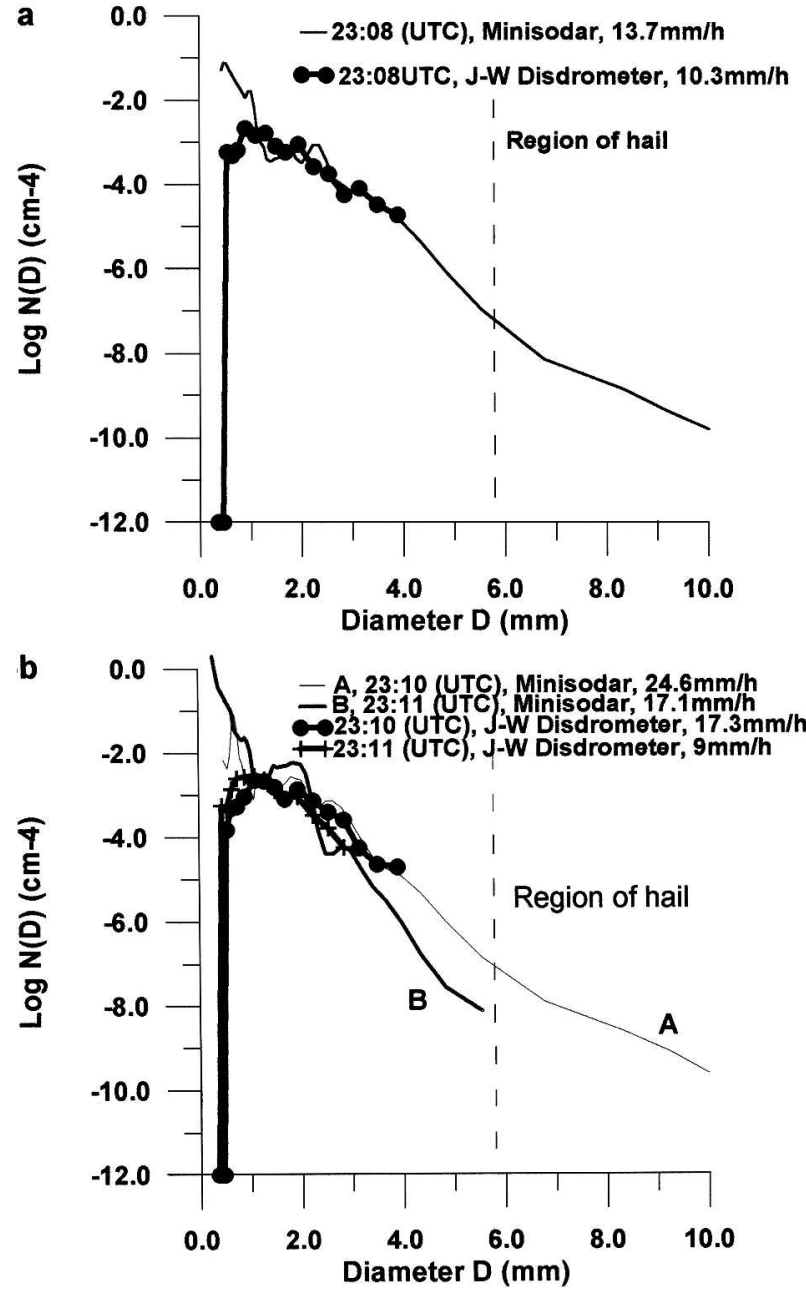

FIG. 6. (a) Comparison of 1-min mean $N(D)$ measured by the minisodar and JW disdrometer during a heavy shower at 2308 UTC on 25 Oct 2002. (b) Same as in (a), but at 2310 UTC for curve A and 2311 UTC for curve B.

$6 \mathrm{~b}$, the $N(D)$ corresponds to a rain rate of $24.6 \mathrm{~mm} \mathrm{~h}^{-1}$ for the minisodar and $17.3 \mathrm{~mm} \mathrm{~h}^{-1}$ for the JW disdrometer; curve B at 2311 UTC led to $17.1 \mathrm{~mm} \mathrm{~h}^{-1}$ for the minisodar and only $9 \mathrm{~mm} \mathrm{~h}^{-1}$ for the JW disdrometer. The measured size distribution $N(D)$ in Fig. 6 corresponds to the heavy shower in point 2 of Fig. 4.

In Fig. 7a, size distribution $N(D)$ measured at 1316 UTC on 27 December 2002 during a heavy thunderstorm leads to a rain rate of $R=111 \mathrm{~mm} \mathrm{~h}^{-1}$ for the minisodar, while only $69.8 \mathrm{~mm} \mathrm{~h}^{-1}$ is given by the JW disdrometer. At 1315 UTC $R=39.1 \mathrm{~mm} \mathrm{~h}^{-1}$ for the minisodar, and $R=23.5 \mathrm{~mm} \mathrm{~h}^{-1}$ for the JW disdrometer, which follow from curve A in Fig. 7b. Curve B in Fig. 7b corresponds to $R=110 \mathrm{~mm} \mathrm{~h}^{-1}$ for the minisodar at 1317 UTC and only $79.4 \mathrm{~mm} \mathrm{~h}^{-1}$ for the JW disdrometer. In Fig. 7, $N(D)$ corresponds to the heavy thunderstorm in point 1 of Fig. 4.

To discover the reason why the rain rates measured 

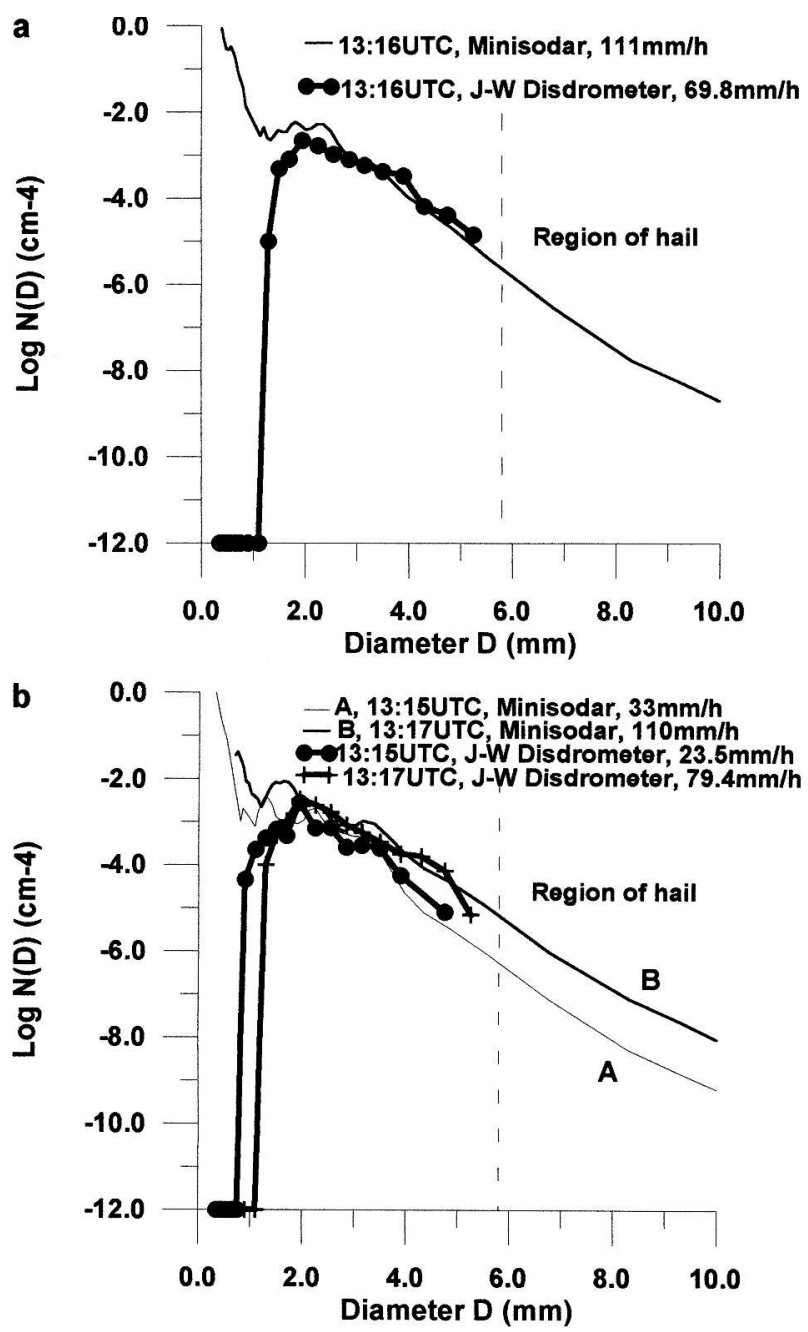

FIG. 7. (a) Same as in Fig. 6a, but during a heavy thunderstorm at 1316 UTC on 27 Oct 2002. (b) Same as in (a), but at 1315 UTC for curve A and 1317 UTC for curve B.

by the minisodar during heavy showers are always higher than those from the JW disdrometer, we compared the measured drop size distributions $N(D)$. For the drop diameter $D$ interval from about $1.5-4.5 \mathrm{~mm}$, both size distributions $N(D)$ agree well, except for some clear modes sometimes appearing in the minisodar $N(D)$. However, no agreement exists for small drops $(D<1 \mathrm{~mm})$ and very large ones $(D>5.25 \mathrm{~mm})$, where the sodar gives much higher values. In view of the working principle of the JW disdrometer, ambient noise greatly disturbs the measurements. During heavy rain, the threshold for drop detection increases as the background noise becomes higher. This leads to the neglecting of drops in the smallest-size channels of the JW disdrometer. For instance, on the 25 October 2002, for the heavy shower shown in Figs. 6a and 6b with $R>$ $15 \mathrm{~mm} \mathrm{~h}^{-1}$, the smallest $4-5$ bins report no drops, that is, $D<0.65 \mathrm{~mm}$ is suppressed. More seriously, on 27
October 2002, during a heavy thunderstorm $(R>100$ $\mathrm{mm} \mathrm{h}^{-1}$ ) with gale force winds, all seven of the smallest bins report no drops, that is, the $N(D)$ for $D<1.1 \mathrm{~mm}$ is lost, as indicated in Figs. 7a and 7b.

In addition, other bins with $D$ above the thresholds have also underestimated the rain rate. Curve B in Fig. $6 \mathrm{~b}$ and curve A in Fig. $7 \mathrm{~b}$ both show heavy rainfall but with many small raindrops underestimated by up to $20 \%$ by the JW disdrometer. The underestimation of small drops by the JW disdrometer has already been reported earlier, for example, in Sheppard and Joe (1994) and Nystuen et al. (1996).

At the large drop size end, the JW disdrometer has a single bin from 4.75 to $5.75 \mathrm{~mm}$. Particles with $D>5.75$ $\mathrm{mm}$ may be lost or included into the largest bin. During heavy showers, we sometimes found that the largest JW bin counts more drops than the minisodar registers, which points to the inclusion into this bin. In addition, the probability for detection of very large drops is higher for the minisodar because of its larger sampling volume.

A further error for the JW disdrometer may also arise from a nonzero mean vertical wind (Sheppard and Joe 1994). This is particularly true for convective rain. Often strong mean vertical wind $\bar{w}$ occurs in these showers, with sometimes quite large fluctuations from minute to minute. For instance, during a strong thunderstorm on 27 October 2002 at 1317 UTC, displayed in curve $\mathrm{B}$ of Fig. $7 \mathrm{~b}$, the 1 -min averages $\bar{w}$ measured by the minisodar were $0,+1.15,+1.16$, and $+1.36 \mathrm{~m} \mathrm{~s}^{-1}$ at heights of $9,11,13$, and $15 \mathrm{~m}$, respectively. As heavy showers are quite heterogeneous, even over a distance of a few meters or seconds, the nonhomogeneity has certainly caused some scatter for the short-term comparison among different sensors.

Please note that the size distribution $N(D)$ in Figs. 6 and 7 contains many very small drops for $D<0.6 \mathrm{~mm}$, which seem unusual for heavy rain. However, we have found that small drops with $D<0.6 \mathrm{~mm}$ exist both in light and heavy rain as shown in Fig. 1. Only the case depicted in Fig. 1c does not show abundant small drops. The large concentration of small drops might be due to very strong wind shear during the strong horizontal wind at the coast of the island Fehmarn in the Baltic Sea.

On the other side, the drops with $D<0.6 \mathrm{~mm}$ contribute only slightly to rain rate in the cases of Figs. 6 and 7. Appling the well-known Marshall-Palmer exponential distribution fitting to the $N(D)$ in Figs. 6 and 7, however, the interval $D<1 \mathrm{~mm}$ contributes less than $3 \%$ to total rain rate.

\section{c. Modes of $N(D)$}

We notice that $N(D)$ modes often appear in Figs. 6 and 7. These modes of $N(D)$ are located at $D \simeq 0.5,0.7$, $0.8-0.9,1.2-1.3,1.8-2.2$, and $2.8-3.2 \mathrm{~mm}$, which is in broad agreement with other investigations. For instance, Steiner and Waldvogel (1987) found the most 
frequent secondary peaks at $D \simeq 0.7,1.1,1.9$, and 3.2 mm (also see, e.g., List et al. 1987; McFarquhar and List 1993).

However, from Figs. 6 and 7, we can also see that not all modes mentioned did occur during a single measurement (1-min average). Hence, there is evidence for modes to be common in $N(D)$, rather than an artifact or an error of the JW disdrometer, as has been argued by some, for example, Sheppard (1990b).

Since each 1-s spectrum is obtained from 10 individual spectra, the measured 1-min mean size distributions $N(D)$ result from an average of 600 spectra, which gives a high probability that the modes of $N(D)$ are realistic and not caused by noise.

\section{d. Mean vertical wind velocity}

The vertical mean wind velocity $\bar{w}$ retrieved from the first moment of the turbulence spectrum, for instance at a height of $6 \mathrm{~m}$, can be as high as $1 \mathrm{~m} \mathrm{~s}^{-1}$ for a 1-min average. A 4-h time series of $\bar{w}$ from 0000 to 0359 UTC on 9 November 2002 is shown in Fig. 8. The wind slowly became stronger during this period.

Updrafts with $0.2-0.7 \mathrm{~m} \mathrm{~s}^{-1}$ were more often observed than downdrafts, particularly at night, because

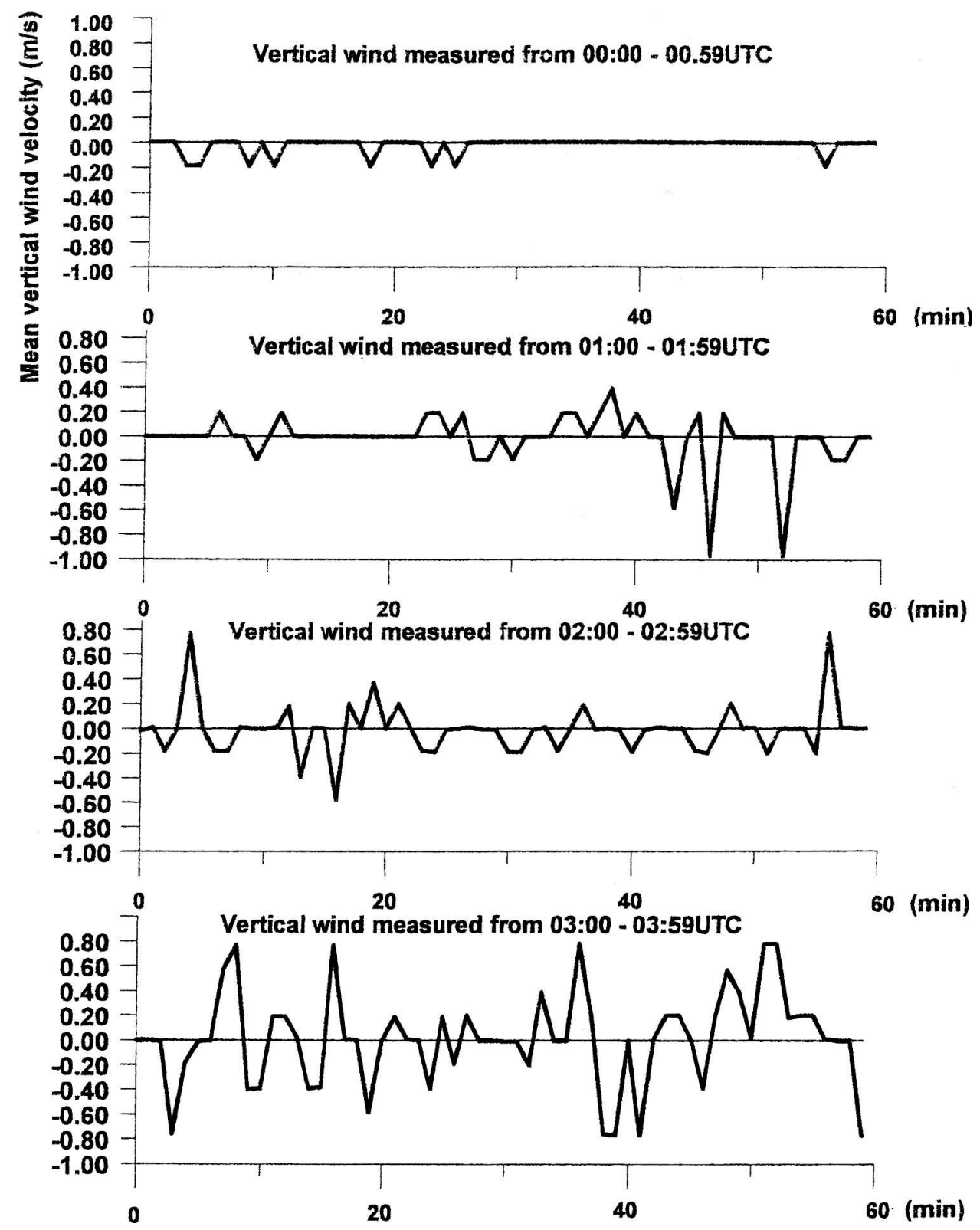

FIG. 8. The 1-min mean vertical wind velocities retrieved from turbulence spectra at 6-m height measured by the minisodar from 0000 to 0359 UTC on 9 Nov 2002. 
the minisodar is located very close to the coast with updrafts during the predominantly westerly wind. Such nonzero mean vertical wind values typically cause $10 \%-40 \%$ errors in rain rates. Without correction, the rain rate for $53 \mathrm{~h}$ of rain would have been $18 \%$ too low.

\section{Sodar measurements of rain/hail mixture and hail}

It is well known that the observation of hail or a mix of rain and hail by microwave radar is difficult. The main reason for this is the large difference of the dielectric constants of ice and water (Bohren and Battan 1980; Chylek et al. 1984; Balakrishnan and Zrnić 1990). Therefore, scattering of electromagnetic waves is sensitive to the mixture compositions (Bohren and Battan 1980, 1982; Aydin et al. 1984, 1990; Battan and Bohren 1986; Longtin et al. 1987) as well as to the water coating of hailstones (Battan et al. 1970; Aydin et al. 1984). A discrimination of the mixture for microwave sounding is thus required, but almost impossible for a single conventional microwave radar. Moreover, an additional uncertainty arises also from a significantly different temperature dependence of attenuation for ice and liquid water.

For acoustic sounding, such problems do not exist because of similar acoustic refractive indices and nearly neglectable acoustic attenuation for water or ice.

For two strong showers (corresponding to points 1 and 2 in Fig. 4 where 1-h averages are shown), the minisodar Doppler spectra indicated a mix of rain and hail. The maximum fall velocity of raindrops is about $9.20 \mathrm{~m} \mathrm{~s}^{-1}$ (Gunn and Kinzer 1949; Atlas et al. 1973). A Doppler velocity spectrum with $w>9.20 \mathrm{~m} \mathrm{~s}^{-1}$ thus should result from hail. In Fig. 9, such a spectrum is given, clearly indicating rain accompanied by hail.

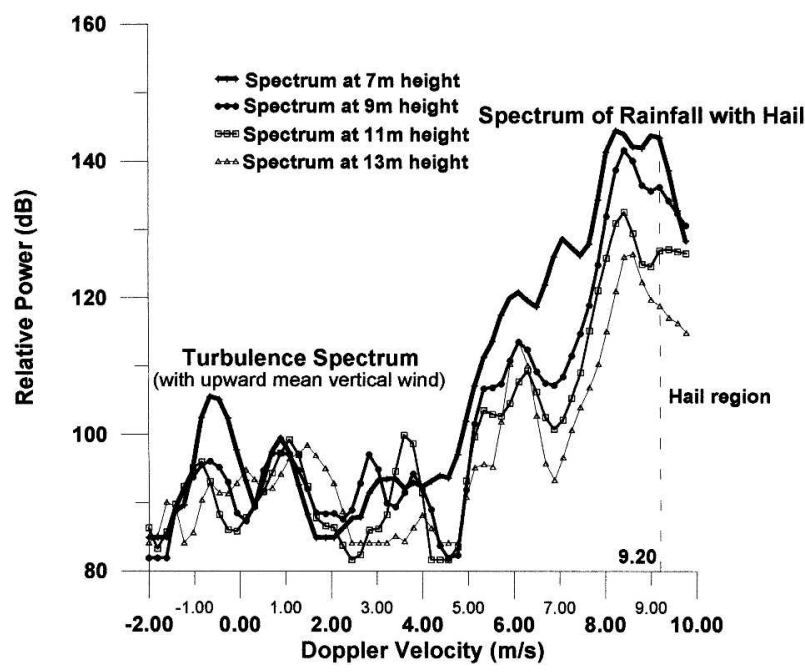

FIG. 9. Doppler power spectrum of rainfall with hail measured by the minisodar during a heavy thunderstorm at 1318 UTC on 27 Oct 2002.
Assuming spherical hydrometeors with the same size, the Rayleigh scattering from rain and hail will be almost the same owing to similar acoustic refractive indices. An empirical relationship between falling speed and diameter for hail is $w(D)=4.51 D^{0.5}$ (Cheng and English 1983) or $w(D)=4.41 D^{0.5}$ (Ulbrich and Atlas 1982), where $w$ is in meters per second and $D$ is the equivalent water drop diameter in mm, whereas $w(D)$ $=4.49 D^{0.5} \mathrm{~m} \mathrm{~s}^{-1}$ (Spilhaus 1948; Atlas et al. 1973) is used for rain. Clearly, these relationships for rainfall and hailfall are very close to each other. The shape of the inclusions is a third-order effect (Bohren and Bat$\tan$ 1982). Obviously, ice, with a density of $0.9 \mathrm{~g} \mathrm{~cm}^{-3}$, can introduce an uncertainty. If the hail is not dominant, this uncertainty can likely be ignored with only small risk.

In summary, we can conclude that for rain with hail, which often occurs in heavy showers, such mixed precipitation can simply be treated as rainfall by neglecting the possible effects of different orientations and shapes of hailstones.

If the precipitation Doppler spectrum peak is above $9.2 \mathrm{~m} \mathrm{~s}^{-1}$ falling speed, it indicates dominance of hail. Then the density of $0.9 \mathrm{~g} \mathrm{~cm}^{-3}$ should be used for the retrieval algorithm. In the case of strong hailstorms, when the precipitation spectrum peak may even lie above $14 \mathrm{~m} \mathrm{~s}^{-1}$ (corresponding to $D>10 \mathrm{~mm}$ ), for example, the Rayleigh scattering assumption is no longer valid, and the Rayleigh-Gans approximation (Matrosov 1992) has to be applied.

\section{Conclusions}

We have developed a high-frequency Doppler minisodar for precipitation parameter measurements. Except for antenna and preamplifier, all other functions of the sodar transmitter and receiver are carried out by software for a digital signal processing (DSP) board and a host PC, making the new single-board minisodar highly reliable, accurate, and flexible at low cost. The digital heterodyne receiver improves the performance, particularly, through background noise suppression during one acoustic burst by spectra averaging.

The long-term operation in a test field has verified that the high-frequency single-board Doppler minisodar has met the design requirements and is likely to become a routine nonattended automatic device for the measurements of drop size distributions and precipitation rates for nearly all kinds of precipitation.

The minisodar observations of rain rates are in good agreement with a JW disdrometer and an optical rain gauge during stratiform rain events. However, for heavy showers, the rain rates measured by the minisodar are always considerably higher than those from the other two instruments. The comparison of the size distributions gave support to the validity of the minisodar measurements. 
The comparison of $N(D)$ also showed that the minisodar agrees well with the JW disdrometer in the diameter range of about $1.5-4.5 \mathrm{~mm}$; however, an underestimation of measured number concentrations at both small and large drop diameters is likely for the JW disdrometer.

In comparison with high-frequency microwave Doppler rain radars and other precipitation gauges, a high-frequency minisodar may be the most promising instrument to measure precipitation rate and precipitation particle size distributions for a mixture of rain and hail. However, for larger hailstones the Rayleigh-Gans approximation should be introduced into the retrieval algorithm. The calibration of the minisodar, however, has to rely on optical rain gauges, Joss-Waldvogel distrometers, or other reliable rain gauges during stratiform rain under low wind speeds.

Acknowledgments. We are grateful for the support of the German Weather Service (DWD), Hamburg, particularly, the staff of the Westermarkelsdorf Weather Station. Without their support, the continuous minisodar operation would not have been possible. We also greatly thank Dr. J. Seltmann of the DWD for providing the Joss-Waldvogel disdrometer data and Dr. K. Bumke of the Maritime Meteorology Department at the Institute for Marine Science of Kiel University for supplying us with the optical rain gauge data. Special thanks are extended to two anonymous reviewers for their critical comments that lead to an improvement of our paper. Within the German Climate Research Programme (DEKLIM) financial support came from the German Ministry for Education and Research, which is gratefully acknowledged.

\section{REFERENCES}

Atlas, D., R. C. Saivastava, and R. S. Sekhon, 1973: Doppler radar characteristics of precipitation at vertical incidence. Rev. Geophys. Space Phys., 11, 1-35.

Aydin, K., A. Seliga, and V. N. Bringi, 1984: Differential radar scattering properties of model hail and mixed phase hydrometeors. Radio Sci., 19, 58-66.

—, Y. Zhao, A. Seliga, and V. N. Bringi, 1990: A differential reflectivity radar hail measurement technique: Observations during the Denver hailstorm of 13 June 1984. J. Atmos. Oceanic Technol., 7, 104-113.

Balakrishnan, N., and D. S. Zrnić, 1990: Estimation of rain and hail rates in mixed-phase precipitation. J. Atmos. Sci., 47, $565-583$.

Battan, L. J., and C. F. Bohren, 1986: Attenuation of microwaves by spherical hail. J. Climate Appl. Meteor., 25, 1155-1159.

- S. R. Browning, and B. M. Herman, 1970: Attenuation of microwaves by wet ice spheres. J. Appl. Meteor., 9, 832-834.

Bohne, A. R., 1982: Radar detection of turbulence in precipitation environments. J. Atmos. Sci., 39, 1817-1837.

Bohren, C. F., and L. J. Battan, 1980: Radar backscattering by inhomogeneous precipitation particles. J. Atmos. Sci., 37, $1821-1827$.

—, and - 1982: Radar backscattering of microwaves by spongy ice spheres. J. Atmos. Sci., 39, 2623-2628.

Bradley, S. G., 1996a: A high-frequency Doppler acoustic precipitation radar. Proc. Eight Int. Symp. Acoustic Remote Sensing,
Moscow, Russia, International Society of Acoustic Remote Sensing of the Atmosphere and Oceans, 3.13-3.18.

_ 1996b: High-frequency acoustic observations of single rain drops. Proc. Eighth Int. Symp. Acoustic Remote Sensing, Moscow, Russia, International Society of Acoustic Remote Sensing of the Atmosphere and Oceans, 3.19-3.21.

_ 1997: Acoustic radar studies of rain microphysics. J. Atmos. Oceanic Technol., 14, 547-553.

Cheng, L., and M. English, 1983: A relationship between hailstone concentration and size. J. Atmos. Sci., 40, 204-213.

Chylek, P. B., R. D. Gupta, N. C. Knight, and C. A. Knight, 1984: Distribution of water in hailstones. J. Climate Appl. Meteor., 23, 1469-1472.

Coulter, R. L., and T. J. Martin, 1986: Results from a high power, high frequency sodar. Atmos. Res., 20, 257-270.

, and T. M. Weckwerth, 1989: Minisodar measurements of rain. J. Atmos. Oceanic Technol., 6, 369-377.

Duvernoy, J., and J. L. Gaumet, 1996: Precipitation hydrometeor characterization by a CW Doppler radar. J. Atmos. Oceanic Technol., 13, 620-629.

Gossard, E. E., 1988: Measuring drop-size distributions in clouds with a clear-air-sensing Doppler radar. J. Atmos. Oceanic Technol., 5, 640-649.

— tions in water clouds from ground-based clear-air-sensing Doppler radar observations. Meteor. Rundsch., 42, 174-180.

,-- , and R. R. Rogers, 1990: Evolution of drop-size distributions in liquid precipitation observed by ground-based Doppler radar. J. Atmos. Oceanic Technol., 7, 815-828.

Grassl, H., S. X. Pang, and F. Y. Mo, 2000: A minisodar on a single DSP board. Proc. 10th Int. Symp. Acoustic Remote Sensing, Auckland, New Zealand, International Society of Acoustic Remote Sensing of the Atmosphere and Oceans, 39-43.

,-- , and -2002 : A comparison of several high frequency Doppler-sodar configurations. Proc. 11th Int. Symp. Acoustic Remote Sensing, Rome, Italy, International Society of Acoustic Remote Sensing of the Atmosphere and Oceans, 123-126.

Gunn, R., and G. D. Kinzer, 1949: The terminal velocity of fall for water droplets in stagnant air. J. Meteor., 6, 243-248.

Hildebrand, P. H., and R. S. Sekhon, 1974: Objective determination of the noise level in Doppler spectra. J. Appl. Meteor., 13, 808-811.

Kinsler, L. E., and A. R. Frey, 1962: Fundamentals of Acoustics. John Wiley \& Sons, 524 pp.

Lee, A. C. L., 1988: The influence of vertical air velocity on the remote microwave measurement of rain. J. Atmos. Oceanic Technol., 5, 727-735.

List, R., 1959: Wachstum von Eis-Wassergemischen im Hagelversuchskanal. Helv. Phys. Acta, 32, 293-296.

- N. R. Donaldson, and R. E. Stewart, 1987: Temporal evolution of drop spectra to collisional equilibrium in steady and pulsating rain. J. Atmos. Sci., 44, 362-372.

Little, C. G., 1972: On the detectability of fog, cloud, rain and snow by acoustic echo-sounding methods. J. Atmos. Sci., 29, 748-755.

Longtin, D. R., C. F. Bohren, and L. J. Battan, 1987: Radar backscattering by large, spongy ice oblate spheroids. J. Atmos. Oceanic Technol., 4, 355-358.

Macklin, W. C., 1961: Accretion in mixed clouds. Quart. J. Roy. Meteor. Soc., 87, 413-424.

Matrosov, S. Y., 1992: Radar reflectivity in snowfall. IEEE Trans. Geosci. Remote Sens., 30, 454-461.

McFarquhar, G. M., and R. List, 1993: The effect of curve fits for the disdrometer calibration on raindrop spectra, rainfall rate, and radar reflectivity. J. Appl. Meteor., 32, 774-782.

Mursch-Radlgruber, E., and D. E. Wolfe, 1993: Mobile highfrequency mini-SODAR and its potential for boundary-layer studies. Appl. Phys., B57, 57-63. 
Nystuen, J. A., J. R. Proni, P. G. Black, and J. C. Wilkerson, 1996: A comparison of automatic rain gauges. J. Atmos. Oceanic Technol., 13, 62-73.

Pang, S. X., and H. Grassl, 1994: Precipitation retrieval from high frequency SODAR measurements. Preprints, Climate Parameters in Radiowave Propagation Prediction (CLIMPAMA)'94, Moscow, Russia, NIIR, 2.7.1-2.7.4.

$\longrightarrow$, and — 1995: Sodar for precipitation measurements. Rep. 160, Max-Planck-Institut für Meteorologie, 46 pp.

- - , and F. Y. Mo, 2000: Additions to our minisodardisdrometer: On-line precipitation retrieval by deconvolution of Doppler spectra and the application of an acoustic filter. Proc. 10th Int. Symp. Acoustic Remote Sensing, Auckland, New Zealand, International Society of Acoustic Remote Sensing of the Atmosphere and Oceans, 228-232.

,-- , and,- 2002 : Special aspects of a high-frequencyminisodar for precipitation measurements. Proc. 11th Int. Symp. Acoustic Remote Sensing, Rome, Italy, International Society of Acoustic Remote Sensing of the Atmosphere and Oceans, 445-448.

Rajopadhyaya, D. K., P. T. May, and R. A. Vincet, 1993: A general approach to the retrieval of raindrop size distributions from wind profiler Doppler spectra: Modeling results. J. Atmos. Oceanic Technol., 10, 710-717.

Ralph, F. M., P. J. Neiman, and D. Ruffieux, 1996: Precipitation identification from radar wind profiler spectral moment data: Vertical velocity histograms, velocity variance, and signal power-vertical velocity correlations. J. Atmos. Oceanic Technol., 13, 545-559.

Sato, T., H. Doji, H. Iwai, I. Kimura, S. Fukao, M. Yamamoto, T. Tsuda, and S. Kato, 1990: Computer processing for deriving drop-size distributions and vertical air velocities from VHF Doppler radar spectra. Radio Sci., 25, 961-973.

Sheppard, B. E., 1990a: Measurement of raindrop size distribu- tions using a small Doppler radar. J. Atmos. Oceanic Technol., 7, 255-268.

- 1990b: Effect of irregularities in the diameter classification of raindrops by the Joss-Waldvogel disdrometer. J. Atmos. Oceanic Technol., 7, 180-183.

—_, and P. I. Joe, 1994: Comparison of raindrop size distribution measurements by a Joss-Waldvogel disdrometer, a PMS 2DG spectrometer, and a POSS Doppler radar. J. Atmos. Oceanic Technol., 11, 874-887.

Spilhaus, A. F., 1948: Raindrop size, shape, and falling speed. J. Meteor., 5, 108-110.

Steiner, M., and A. Waldvogel, 1987: Peaks in raindrop size distributions. J. Atmos. Sci., 44, 3127-3133.

Ulbrich, C. W., 1992: Algorithm for determination of rainfall integral parameters using reflectivity factor and mean Doppler fall speed at vertical incidence. J. Atmos. Oceanic Technol., 9 120-128.

- and D. Atlas, 1982: Hail parameters: A comprehensive digest. J. Appl. Meteor., 21, 22-42.

Wakasugi, W., A. Mizutani, and M. Matsuo, 1986: A direct method for deriving drop-size distribution and vertical air velocity from VHF Doppler radar spectra. J. Atmos. Oceanic Technol., 3, 623-629.

,$- \ldots$, and $\_$1987: Further discussion on deriving dropsize distribution and vertical air velocities directly from VHF Doppler radar spectra. J. Atmos. Oceanic Technol., 4, 170 179

Weill, A., C. Klapisz, and F. Baudin, 1986: The CRPE minisodar: Applications in micrometeorology and in physics of precipitations. Atmos. Res., 20, 317-333.

Wilson, J. W., 1970: Integration of radar and raingage data for improved rainfall measurement. J. Appl. Meteor., 9, 489-497. 